\title{
Studies on Zinc-Containing Poly(urethane-ether)s
}

\author{
Rangasamy JAYAKUMAR ${ }^{\dagger, \dagger \dagger}$ and Sankaran NANJUNDAN \\ Department of Chemistry, Anna University, Chennai-600 025, India
}

(Received May 15, 2003; Accepted July 21, 2003)

\begin{abstract}
Zinc-containing poly(urethane-ether)s (PUEs) were synthesized by the reaction of hexamethylene diisocyanate (HMDI) or toluylene 2,4-diisocyanate (TDI) with a mixture of zinc salt of mono(hydroxyethoxyethyl)phthalate $\left[\mathrm{Zn}(\mathrm{HEEP})_{2}\right]$ and poly(ethylene glycol) $\left(\mathrm{PEG}_{300}\right.$ or $\mathrm{PEG}_{400}$ ) by using di- $n$-butyltin dilaurate as a catalyst. Blank PUEs without $\left[\mathrm{Zn}(\mathrm{HEEP})_{2}\right]$ were also prepared by reaction of $\mathrm{PEG}_{300}$ or $\mathrm{PEG}_{400}$ with HMDI or TDI. Thus prepared PUEs were characterized by FT-IR, ${ }^{1} \mathrm{H}$ and ${ }^{13} \mathrm{C}$ NMR, solid-state ${ }^{13} \mathrm{C}-\mathrm{CP}-\mathrm{MAS}$ NMR, viscosity, solubility, and X-ray diffraction studies. Thermal properties of the polymers were studied by using thermogravimetric analysis and differential scanning calorimetry.

KEY WORDS Zinc-Containing Poly(urethane-ether)s / Spectral Studies / Thermal Properties / Viscosity / X-ray Diffraction Studies /
\end{abstract}

Polyurethanes (PUs) are a very extensive class of polymers. PUs have wide range of industrial applications such as coating, adhesives, and biomedical materials etc., and they are well known for their mechanical properties. PUs are becoming increasingly important as engineering materials, because it has excellent abrasion resistance and properties of both elastomer and plastics. ${ }^{1-4}$ Some PUs are used as rocket motor liners for securing the composite propellant grain within the rocket motor. PUs possesses excellent mechanical and physical properties, high combustion resistance, and wear resistance with a broad temperature range for use, good blood and tissue compatibility. ${ }^{5}$ PUs are usually composed of multi-phase segments. These alternating hard and soft segment structures are suitable for many applications by imparting various properties.

PUs with flexible polyol backbone have generally good retention properties at low temperatures which make them suitable candidates for use in adhesives, coatings etc., under cryogenic conditions. ${ }^{6}$ Urethanebased materials are of commercial interest in many applications because of their excellent properties such as abrasion resistance, low temperature flexibility, high strength and aging and chemical resistance. The polyurethane adhesives are used in substrates such as glass, wood, leather, plastics, rubber, metal, concrete, and ceramic. ${ }^{7-11}$ Incorporation of metal and functional groups into the polymers has led to wide applications such as aqueous thickeners, impregnates, textile sizers, ${ }^{12,13}$ resins ${ }^{14-16}$ and catalysts. ${ }^{17}$ Ionic diols containing ionic linkages between $\mathrm{COO}^{-}$and $\mathrm{M}^{++}$are of interest and are very important starting materials for the synthesis of ionic polymers in which the metal is firmly incorporated into the backbone of the polymer chain. ${ }^{18-28}$

The present paper deals with the synthesis and characterization of hexamethylene diisocyanate (HMDI) and toluylene 2,4-diisocyanate (TDI) based poly(urethane-ether)s (PUEs) from zinc salt of mono(hydroxyethoxyethyl)phthalate $\left[\mathrm{Zn}(\mathrm{HEEP})_{2}\right]$ and poly(ethylene glycol) $\left(\mathrm{PEG}_{300}\right.$ or $\left.\mathrm{PEG}_{400}\right)$.

\section{EXPERIMENTAL}

\section{Materials}

Phthalic anhydride (Merck), diethylene glycol (Merck), $\mathrm{PEG}_{300}$ and $\mathrm{PEG}_{400}$ (Merck), di- $n$-butyltin dilaurate (DBTDL) (Fluka), HMDI and TDI (Fluka) and zinc acetate (Merck) were used as received. The solvents such as acetone, methyl ethyl ketone, water, methanol, dimethyl formamide (DMF), dimethyl sulphoxide (DMSO), dimethyl acetamide (DMAc), tetrahydrofuran, benzene, toluene, $m$-cresol, and chloroform were purified by standard procedures. $\mathrm{Zn}(\text { HEEP })_{2}$ was synthesized as reported in our previous paper. ${ }^{19}$

\section{Synthesis of PUES}

$\mathrm{Zn}(\text { HEEP })_{2}(0.008 \mathrm{~mol})$ and $\mathrm{PEG}_{300}$ or $\mathrm{PEG}_{400}$ $(0.008 \mathrm{~mol})$ were dissolved in $100 \mathrm{~mL}$ of DMSO in a $500 \mathrm{~mL}$ three necked round bottom flask equipped with a nitrogen inlet, a condenser and a dropping funnel. Then HMDI or TDI $(0.016 \mathrm{~mol})$ dissolved in $20 \mathrm{~mL}$ of DMSO was added to the mixture maintained at $95^{\circ} \mathrm{C}$

\footnotetext{
${ }^{\dagger}$ To whom correspondence should be addressed(Fax: +82-063-270-2306, E-mail: jayakumar77@yahoo.com).

${ }^{\dagger}$ Present Address: Division of Environmental and Chemical Engineering, Engineering Research Institute, Chonbuk National University, Chonju 561-756, Korea.
} 


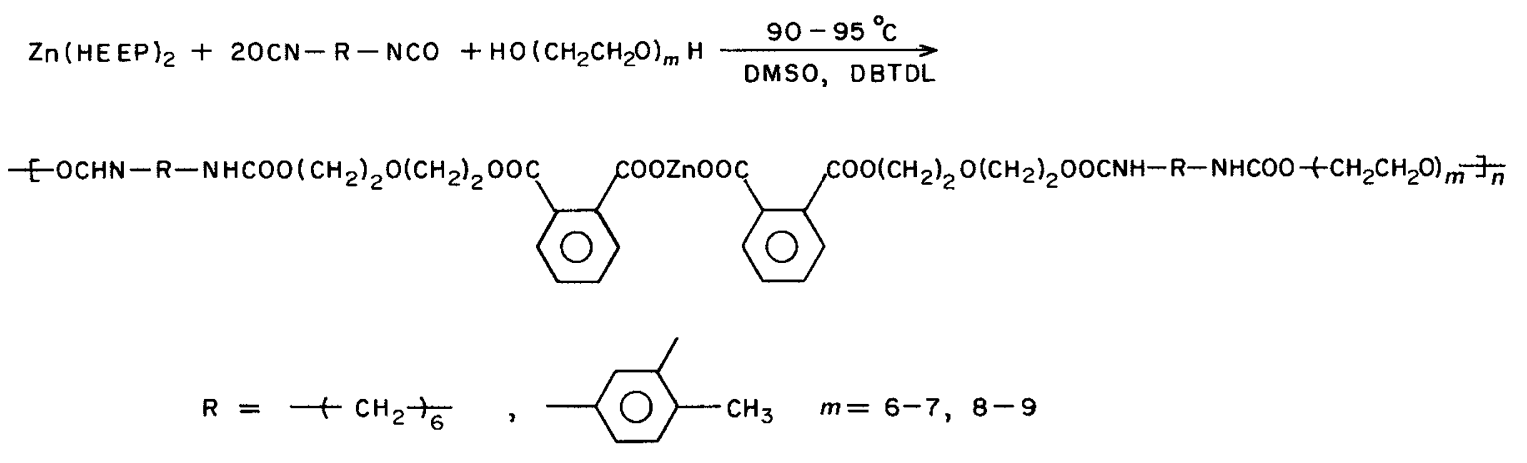

II

\begin{tabular}{c|c|c|c|c} 
Polymer & I & II & III & IV \\
\hline R & I & II & I & II \\
$m$ & $6-7$ & $6-7$ & $8-9$ & $8-9$
\end{tabular}

Scheme 1. Synthesis of zinc-containing PUEs.

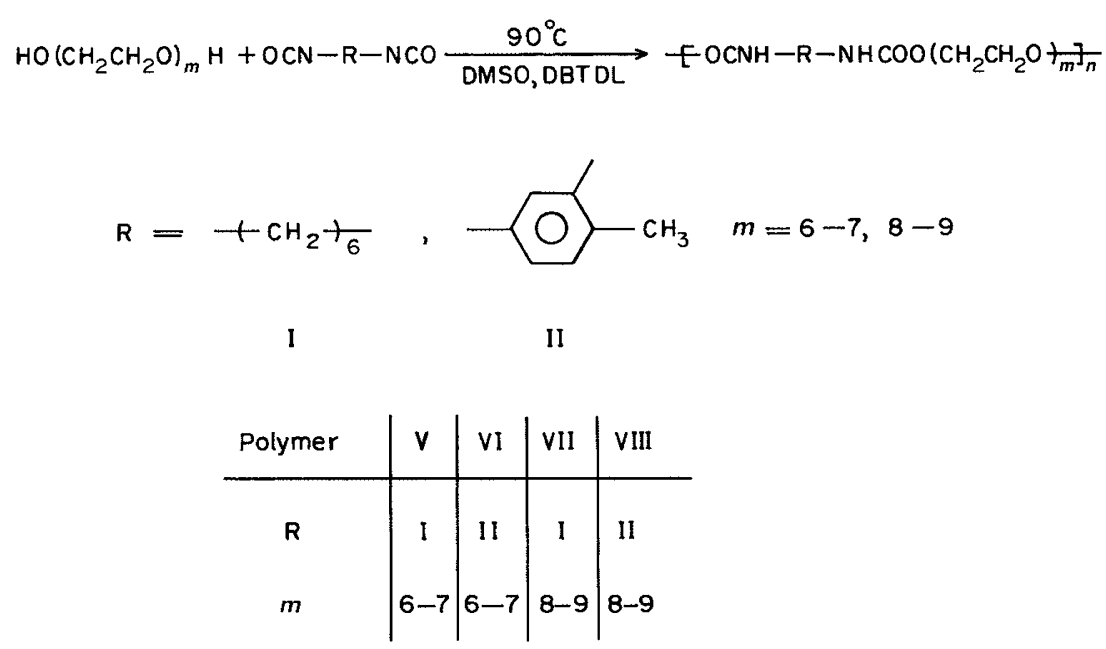

Scheme 2. Synthesis of blank PUEs.

over a period of $30 \mathrm{~min}$ in the presence of 2-3 drops of DBTDL as a catalyst. The synthesis was completely carried out under a nitrogen atmosphere. Then the reaction mixture was diluted with DMSO and filtered. The filtrate was poured into an excess quantity of methanol under vigorous stirring. The separated product was washed several times with methanol followed by acetone. The precipitate was dried in vacuo at $75^{\circ} \mathrm{C}$ for $24 \mathrm{~h}$. Scheme 1 shows the reactions involved in the synthesis of PUEs based on Zn(HEEP) $)_{2}$. The blank PUEs were also prepared by the same method without zinccontaining monomer. Scheme 2 shows the reactions involved in the synthesis of blank PUEs.

\section{Measurements}

The infrared (IR) spectra of the polymers were recorded on a Testscan Shimadzu FT-IR 8000 series spectrophotometer at room temperature with the $\mathrm{KBr}$ pellet method. The ${ }^{1} \mathrm{H} \&{ }^{13} \mathrm{C}$ NMR \& DEPT spectra of the polymers were recorded on a JEOL GSX$400 \mathrm{MHz}$ spectrometer in DMSO- $d_{6}$ using tetramethylsilane (TMS) as an internal standard. The solidstate ${ }^{13} \mathrm{C}$-CP-MAS NMR spectra were obtained using a Bruker MSL $75 \mathrm{MHz}$ spectrometer with adamantine as a chemical shift reference. The thermogravimetric analysis (TGA) was performed with a Mettler3000 thermal analyzer using $2 \mathrm{mg}$ of the sample at a heating rate of $20^{\circ} \mathrm{C} \mathrm{min}^{-1}$ in air. The differential scanning calorimetric analysis was carried out using a DSC V4.OB Dupont 2100 model differential scanning calorimeter at a heating rate of $10^{\circ} \mathrm{C} \mathrm{min}^{-1}$ under a nitrogen atmosphere. The X-ray diffractograms were recorded according to a powder method with a Philips PW 1710 diffractometer using $\mathrm{CuK} \alpha$ radiation. The in- 
Table I. Synthesis and viscosity data of zinc-containing PUEs

\begin{tabular}{llccl}
\hline $\begin{array}{l}\text { Polymer } \\
\text { No. }\end{array}$ & Polymer code $\left(\mathrm{dL} \mathrm{g}^{-1}\right)$ & $\begin{array}{c}\text { Yield } \\
(\%)\end{array}$ & $\begin{array}{c}\eta_{\text {inh }} \\
\left(\mathrm{dL} \mathrm{g}^{-1}\right)\end{array}$ & $\begin{array}{l}\text { External } \\
\text { appearance }\end{array}$ \\
\hline I & $\mathrm{Zn}(\mathrm{HEEP})_{2}-\mathrm{PEG}_{300}$-HMDI & 78 & 0.093 & White \\
II & $\mathrm{Zn}(\mathrm{HEEP})_{2}-\mathrm{PEG}_{300}$-TDI & 72 & 0.089 & Yellowish White \\
III & $\mathrm{Zn}(\mathrm{HEEP})_{2}-\mathrm{PEG}_{400}$-HMDI & 81 & 0.103 & White \\
IV & $\mathrm{Zn}(\mathrm{HEEP})_{2}-\mathrm{PEG}_{400}$-TDI & 73 & 0.101 & Yellowish White \\
V & PEG $_{300}$-HMDI & 78 & 0.192 & White \\
VI & PEG $_{300}$-TDI & 72 & 0.176 & Slightly Yellow \\
VII & PEG $_{400}$-HMDI & 84 & 0.202 & White \\
VIII & PEG $_{400}$-TDI & 82 & 0.190 & Slightly Yellow \\
\hline
\end{tabular}

herent viscosity $\eta_{\text {inh }}$ of the polymers in DMSO was determined using an Ubbelohde-viscometer at $40^{\circ} \mathrm{C}$. The flow time for the solvent as well as the polymer solution $\left(1.0 \mathrm{~g} \mathrm{dL}^{-1}\right)$ was determined. The solubility of the polymers was tested in various polar and non-polar solvents by taking $10 \mathrm{mg}$ of the polymers in $2 \mathrm{~mL}$ of different solvents in a closed test tube and set aside for one day.

\section{RESULTS AND DISCUSSION}

\section{Synthesis}

The synthesis of zinc-containing PUEs was carried out in DMSO solvent. $\mathrm{Zn}(\text { HEEP) })_{2}$ was not soluble in other solvents like dioxane, toluene, xylene and acetone, and hence the polyaddition reaction did not proceed smoothly in these solvents. During the synthesis of the polymers, the mole ratio of diisocyanate:diol $\left(\mathrm{Zn}(\mathrm{HEEP})_{2}\right.$ and $\mathrm{PEG}_{300}$ or $\mathrm{PEG}_{400}$ ) was kept to be 1:1 to avoid the formation of crosslinkages. The crosslinked product formed if any was filtered off after stirring the product with excess of DMSO to dissolve the linear polymer. The precipitated polymer was washed with acetone to remove unreacted $\mathrm{Zn}(\mathrm{HEEP})_{2}$ and then with methanol followed by acetone. With the help of $\mathrm{Zn}(\mathrm{HEEP})_{2}, \mathrm{PEG}_{300}$ or $\mathrm{PEG}_{400}$ and HMDI or TDI, four PUEs were prepared by the same method. The PUEs are encoded as $\mathrm{Zn}(\mathrm{HEEP})_{2}-\mathrm{PEG}_{300}-\mathrm{HMDI}$ I, Zn(HEEP) $)_{2}-\mathrm{PEG}_{300}$-TDI II, Zn(HEEP) $)_{2}-\mathrm{PEG}_{400}-$ HMDI III, and Zn(HEEP) $)_{2}-\mathrm{PEG}_{400}$-TDI IV. The blank PUEs are encoded as $\mathrm{PEG}_{300}$-HMDI $\mathbf{V}, \mathrm{PEG}_{300}$-TDI VI, PEG 400 -HMDI VII, and $\mathrm{PEG}_{400}$-TDI VIII. The yields of the PUEs were good in all the cases. The synthesis data of PUEs and blank PUEs are given in Table I. The PUEs were insoluble in methanol, ethanol, acetone, ethyl methyl ketone, carbon tetrachloride, ethyl acetate, $n$-hexane, benzene, toluene, tetrahydrofuran, and xylene. However, they were soluble in highly polar solvents such as DMF, DMSO, and DMAc.

\section{Characterization of PUES}

FT-IR Spectra. The PUEs show a broad absorp-

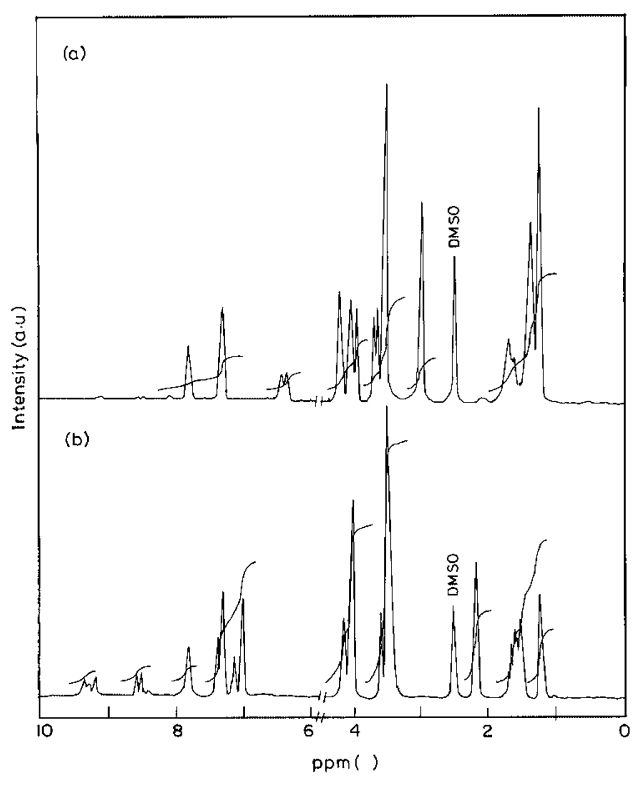

Figure 1. ${ }^{1} \mathrm{H}$ NMR spectra of PUEs: (a) I and (b) II.

tion band between 3338 and $3292 \mathrm{~cm}^{-1}$ is due to $\mathrm{N}-$ $\mathrm{H}$ stretching. The absorption band at $3055-3031 \mathrm{~cm}^{-1}$ is due to the aromatic $\mathrm{C}-\mathrm{H}$ stretching. The absorption bands at 2939-2925 and $2857-2850 \mathrm{~cm}^{-1}$ are due to the asymmetrical and symmetrical $\mathrm{C}-\mathrm{H}$ stretching of methylene and methyl groups. The peaks around $1707-1685 \mathrm{~cm}^{-1}$ are due to the carbonyl stretching of urethane and ester groups. The carboxylate ion of the zinc salt gives two broad peaks between 1604-1557 and $1410-1397 \mathrm{~cm}^{-1}$. This confirms the presence of ionic linkages in the PUEs. These bands were not observed in metal-free analogues of these polymers (blank polymers). The peak at $1107-1080 \mathrm{~cm}^{-1}$ are attributed to the $\mathrm{C}-\mathrm{O}$ stretching of the ester group. The $\mathrm{C}-\mathrm{H}$ out of plane bending vibrations of aromatic rings is observed between 752 and $743 \mathrm{~cm}^{-1}$.

${ }^{1} H$ NMR Spectra. The ${ }^{1} \mathrm{H}$ NMR spectra of PUEs I and II are shown in Figure 1. The TDI-based PUEs show peaks at 9.29-9.24 and $8.43-8.39 \mathrm{ppm}$ are due to the urethane $\mathrm{N}-\mathrm{H}$ protons whereas the HMDI-based PUEs show the corresponding peak at $6.64-6.56 \mathrm{ppm}$. The aromatic protons of HMDI-based PUEs show res- 


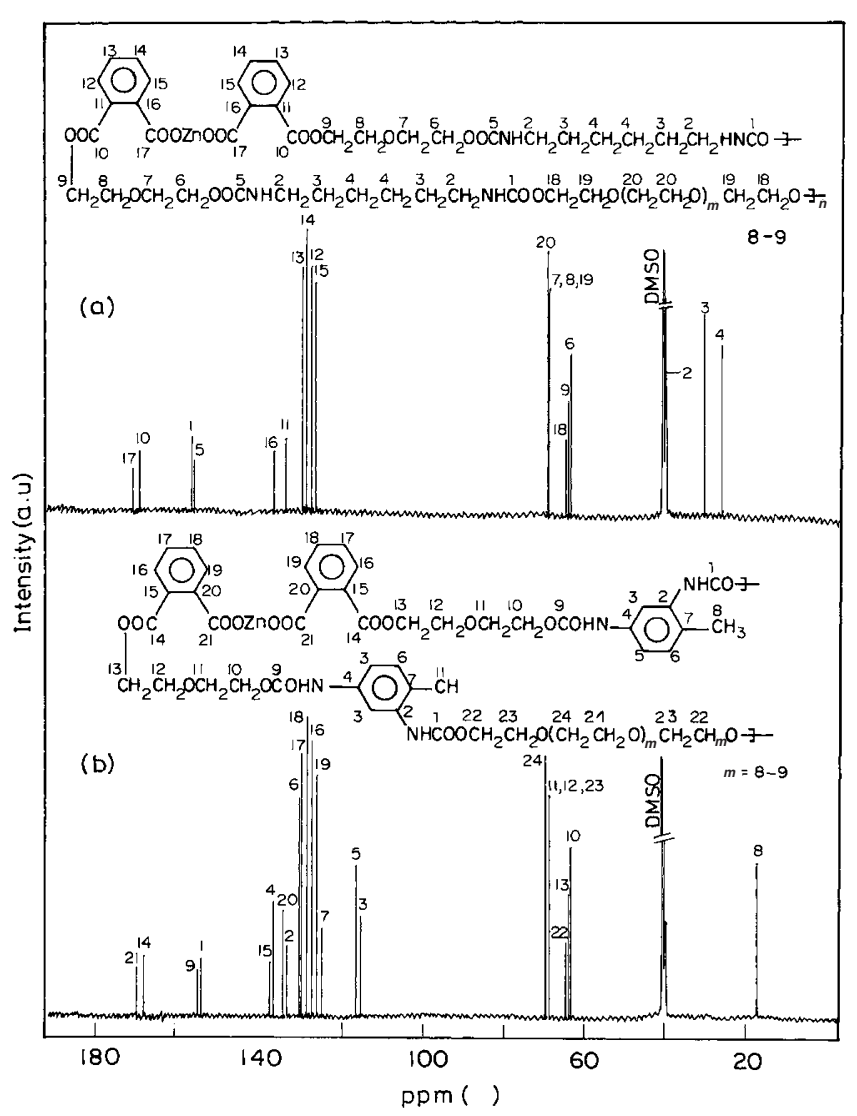

Figure 2. ${ }^{13} \mathrm{C}$ NMR spectra of PUEs: (a) III and (b) IV.

onance signals at 7.83-7.25 ppm whereas those of TDIbased PUEs show resonance signals at 7.88-7.08 ppm. The peak at $4.25-4.06 \mathrm{ppm}$ is due to the methyleneoxy group attached to the $-\mathrm{COPh}$ and $-\mathrm{CONH}$ groups. The resonance signal at $3.54-3.52 \mathrm{ppm}$ is due to the $-\mathrm{CH}_{2} \mathrm{OCH}_{2}-$ group. The methylene group attached to the $-\mathrm{NH}$ group shows signal between 2.98 and $2.95 \mathrm{ppm}$. The methyl group attached to the aromatic ring shows resonance signal at $2.14 \mathrm{ppm}$. The peak at $1.78-1.56 \mathrm{ppm}$ is due to methylene group attached to methylenoxy group. The other methylene groups show resonance signal between 1.46 and $1.21 \mathrm{ppm}$.

${ }^{13} C$ NMR Spectra. The ${ }^{13} \mathrm{C}$ NMR spectra of the PUEs III and IV are shown in Figure 2. The peaks at $170.83-168.67 \mathrm{ppm}$ are due to the carboxylate and ester carbonyl carbon of the PUEs. The PUEs show signals at $156.29-153.54 \mathrm{ppm}$ are due to the urethane carbonyl carbon. The aromatic carbon signals due to HMDI-based PUEs are observed between 136.72 and $125.52 \mathrm{ppm}$ and those of TDI-based PUEs shows between 137.25 and $115.12 \mathrm{ppm}$. The methyleneoxy carbon of $\mathrm{PEG}_{300}$ or $\mathrm{PEG}_{400}$ unit in the PUEs shows resonance signal at $69.48-69.39 \mathrm{ppm}$. The signal is observed between $68.70-68.15 \mathrm{ppm}$ is due to the $-\mathrm{CH}_{2} \mathrm{OCH}_{2}-$ group. The methylene group attached to the - $\mathrm{OCOPh}$ and the -OCONH groups shows peak between $64.32-64.22$ and $63.53-63.28 \mathrm{ppm}$, respectively.

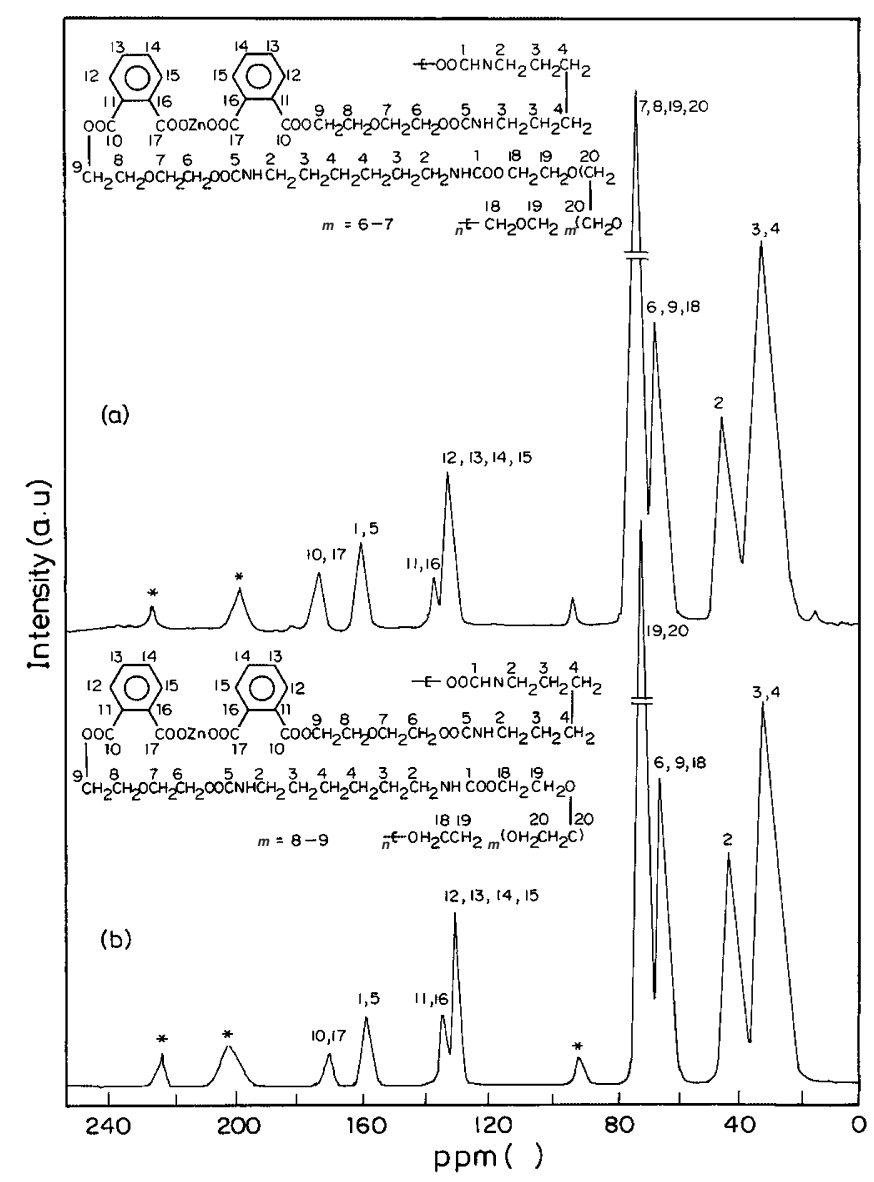

Figure 3. Solid state ${ }^{13} \mathrm{C}-\mathrm{CP}-\mathrm{MAS}$ NMR spectra of PUEs: (a) I and (b) III.

The signal due to the methylene group attached to the $-\mathrm{NH}$ group is overlapped with the DMSO peak. The other methylene carbon signals are observed between $32.51-26.68 \mathrm{ppm}$. The methyl group attached to the aromatic ring of the TDI-based PUEs shows peak at $17.33-17.28 \mathrm{ppm}$.

\section{Solid-State ${ }^{13} C$-CP-MAS NMR Spectra}

Figure 3 shows the solid-state ${ }^{13} \mathrm{C}$-CP-MAS NMR spectra of the PUEs I and III. The PUEs show broad peak at $172.93-172.81 \mathrm{ppm}$ is due to the carboxylate and ester carbonyl carbon of PUEs. The urethane carbonyl carbon shows peak at $157.53-154.12 \mathrm{ppm}$. The HMDI-based PUEs show a broad peak due to the aromatic carbons at $135.16-129.30 \mathrm{ppm}$. The peak at $70.27-70.06 \mathrm{ppm}$ is due to the methyleneoxy carbon of $\mathrm{PEG}_{300}$ or $\mathrm{PEG}_{400}$ unit in the PUEs. The methyleneoxy carbon attached to the $-\mathrm{OCOPh}$ and the $-\mathrm{OCONH}$ groups show a peak at $65.55-65.12 \mathrm{ppm}$. The methylene group attached to $-\mathrm{NH}$ group shows peak around at $42.56-42.53 \mathrm{ppm}$ in the case of HMDI-based PUEs. The peak is missing in the ${ }^{13} \mathrm{C}$ NMR spectra of the polymers in DMSO. The peak at $30.17-30.06 \mathrm{ppm}$ is due to the other methylene groups. 
Table II. TGA and DSC data of zinc-containing PUEs

\begin{tabular}{lcccccccc}
\hline \multirow{2}{*}{$\begin{array}{l}\text { Polymer } \\
\text { No. }\end{array}$} & \multirow{2}{*}{$\begin{array}{c}T_{\mathrm{g}} \\
\left({ }^{\circ} \mathrm{C}\right)\end{array}$} & $\begin{array}{c}\text { IDT } \\
\left({ }^{\circ} \mathrm{C}\right)\end{array}$ & \multicolumn{5}{c}{ Temperature at weight loss $\left({ }^{\circ} \mathrm{C}\right)$} & \multirow{2}{*}{$\begin{array}{c}\text { Weight loss } \\
\text { at } 800{ }^{\circ} \mathrm{C}\end{array}$} \\
\hline I & 4.1 & 197 & 265 & $30 \%$ & $60 \%$ & $80 \%$ & $90 \%$ & $(\%)$ \\
II & 6.9 & 215 & 265 & 295 & 326 & 529 & 705 & 92.2 \\
III & 3.5 & 202 & 279 & 305 & 345 & 621 & 722 & 92.3 \\
IV & 5.8 & 230 & 235 & 318 & 345 & 523 & 718 & 92.8 \\
V & -30.2 & 234 & 313 & 339 & 365 & 427 & 531 & 100 \\
VI & -19.4 & 229 & 301 & 321 & 340 & 371 & 503 & 100 \\
VII & -37.1 & 246 & 322 & 346 & 361 & 407 & 504 & 100 \\
VIII & -26.7 & 241 & 320 & 343 & 357 & 401 & 483 & 100 \\
\hline
\end{tabular}

\section{Inherent Viscosity}

The inherent viscosity data of PUEs in DMSO at $40{ }^{\circ} \mathrm{C}$ are given in Table I. The viscosities of PUEs are found to be low when compared with that of blank PUEs. This is due to the presence of the ionic linkages in the polymer chains. The inherent viscosities of the PUEs are considerably lower than their non-metal analogues, ${ }^{21-28}$ as is generally known for all metal-containing polyurethanes and poly(urethaneurea)s. The reason for the low viscosity may be that in these polymers the molecular weight builds up may not be very high and there may also be partial reversible dissociation of the metal oxygen bonds leading to lower molecular weight fragments in solutions. ${ }^{22-25}$ With increase in the soft segment content and its length and decrease the metal content in the PUEs, the viscosity increases due to the presence of lower number of ionic linkages. So, the PUEs based on $\mathrm{PEG}_{400}$ show higher viscosities than the PUEs based on $\mathrm{PEG}_{300}$. The HMDI-based PUEs show higher inherent viscosities than the TDI-based PUEs. This is due to the higher hydrodynamic volume of HMDI-based polymers will be more than TDI-based polymers.

\section{Thermogravimetric Analysis}

The TGA data of PUEs are given in Table II. The initial decomposition temperature (IDT) of PUEs shows the range between 197 and $230^{\circ} \mathrm{C}$. The IDT of the PUEs are slightly lower than that of blank PUEs. However, their decomposition temperatures are lesser than those of blank PUEs. This result indicates that the metal acts as a catalyst and facilitates the first stage decomposition but retards the rate of decomposition on further stages. All the PUEs showed multiple stage decomposition. The first stage may be considered to be urethane-ether scission followed by the formation of isocyanate and hydroxyl components. ${ }^{23}$ The second stage perhaps involves cyclization and secondary degradation. The third stage corresponds to the formation of $\mathrm{ZnCO}_{3}$. The PUEs based on $\mathrm{PEG}_{400}$ showed higher IDT than $\mathrm{PEG}_{300}$. The initial decomposition takes place at the urethane linkages, and the numbers of urethane linkages are more in a unit length of $\mathrm{PEG}_{300}$ based PUEs than that in $\mathrm{PEG}_{400}$ based PUEs. The blank PUEs showed $100 \%$ weight loss at $650^{\circ} \mathrm{C}$, indicating that PUEs exhibit good thermal stability than the blank PUEs. In all the cases of the polymers the residual weight at $800^{\circ} \mathrm{C}$ roughly corresponds to the amount of $\mathrm{ZnO}$ formed at this temperature. The TDIbased polymers show higher IDT than the HMDI-based PUEs. This may due to the presence of stiff phenylene ring present in the polymer chain.

\section{Glass Transition Temperature $\left(T_{\mathrm{g}}\right)$}

The $T_{\mathrm{g}}$ data are given in Table II. The $T_{\mathrm{g}}$ values of the zinc-containing PUEs ranges from 4.1 to $6.9^{\circ} \mathrm{C}$. All the PUEs showed single $T_{\mathrm{g}}$ value. This may be due to the absence of formation of mixture of homopolymer or block copolymer. ${ }^{28}$ This also indicates that the absence of heterogeneous mixing of hard (urethane unit) and soft segment (polyol) in the polymer matrix. The difference in the $T_{\mathrm{g}}$ values between TDI and HMDIbased PUEs is not that much high. This is reason for those HMDI-based polymers have flexible chain, due to the increase in the crystallinity of HMDI-based polymers (revealed by X-ray studies), the $T_{\mathrm{g}}$ value increase and they become close to that of TDI-based PUEs. The $T_{\mathrm{g}}$ value of PUEs decreases with increase in the soft segment.

\section{$X$-ray Diffraction}

Figure 4 shows the XRD pattern of the PUEs. The X-ray diffraction studies show that the HMDI-based PUEs are partially crystalline in nature, whereas the TDI-based PUEs are amorphous in nature. This may due to the folding of the hexmethylene unit present in the backbone of the PUEs. The HMDI-based polymers show some crystalline nature. This was also confirmed by the solubility studies of the PUEs in DMSO. The TDI-based PUEs were more easily soluble in DMSO 


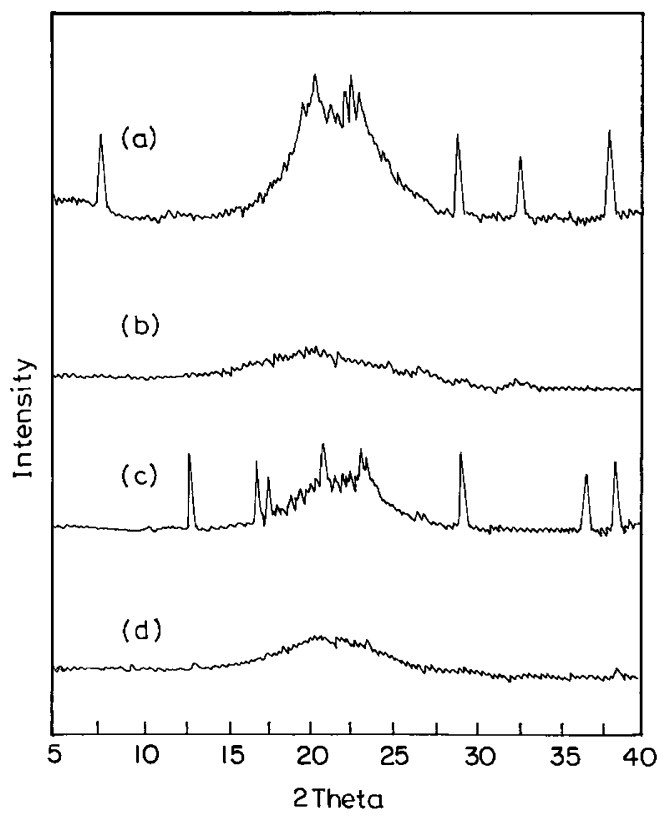

Figure 4. XRD patterns of PUEs: (a) I, (b) II, (c) III, and (d) IV.

than the HMDI-based PUEs. The HMDI-based polymers showed few sharp peaks around at $2 \theta=20-25^{\circ}$.

\section{CONCLUSIONS}

Zinc containing poly(urethane-ether)s were prepared by the reaction of HMDI or TDI with $\mathrm{Zn}[\mathrm{HEEP}]_{2}$ and $\mathrm{PEG}_{300}$ or $\mathrm{PEG}_{400}$. The polymers are soluble in DMF, DMSO, and DMAc and insoluble in most of the other organic solvents. Thermal properties of the polymers showed that the TDI-based PUEs are higher stability than the respective HMDI-based PUEs. The inherent viscosities of the polymers were found to be very low due to chain dissociation in DMSO. X-ray diffraction pattern of the polymers reveals that the TDI-based PUEs are amorphous and HMDI-based PUEs are partially crystalline.

Acknowledgment. R. Jayakumar gratefully acknowledges the award of Senior Research Fellowship from Council of Scientific and Industrial Research (CSIR), India for his research work.

\section{REFERENCES}

1. I. Keiji, "Handbook of Polyurethane Resins," The Nikkan Kogyo Shimbun Ltd., Tokyo, 1987, chapt. 1.
2. G. Woods, "The ICI polyurethanes book," John Wiley \& Sons Ltd., Chichester, 1990, chapt. 1.

3. M. J. Comstock, in "Urethane Chemistry and Applications," ACS Symposium Series, No. 172, American Chemical Society, Washington, D.C., 1981, chapt. 1.

4. W. Meckel, W. Goyert, and W. Wieder, in "Thermoplastic elastomers," N. R. Legge, G. Holden, and H. E. Schroeder, Eds., Hanser Gardner Publications, New York, N.Y., 1987, chapt. 2.

5. C. Hepburn, "Polyurethane Elastomers," 2nd ed, Elsevier Science Publishers B.V., Amsterdam, 1991.

6. P. Radhakrishnan Nair, C. P. Ragunathan Nair, and D. J. Francis, Eur. Polym. J., 33, 89 (1997).

7. Y. C. Lai, E. T. Quinn, and P. L. Valint, Polym. Prep. (Am. Chem. Soc., Div. Polym. Chem.), 33 (1), 1058 (1992).

8. R. R. Roesler, W. Cibulas, and M. B. Bassi, Am. Paint. Coat. $J .$, 3, 41 (1993).

9. B. G. Crowther, Rapra. Rev. Rep., 8, 6 (1996).

10. N. Nash and A. Pajerski, Adhes. Age., 9, 6 (1995).

11. D. Las and P. Cranley, Adhes. Age, 5, 6 (1994).

12. H. Matsuda and K. Kanaoka, J. Appl. Poym. Sci., 30, 1229 (1985).

13. H. Matsuda, J. Appl. Polym. Sci., 23, 2603 (1970).

14. H. Matsuda and S. Takechi, J. Polym. Sci., Part A: Polym. Chem., 28, 1895 (1990).

15. H. Matsuda, J. Appl. Polym. Sci., 22, 2093 (1978).

16. H. Matsuda, J. Polym. Sci., Part A: Polym. Chem., 15, 2239 (1977).

17. H. Matsuda, J. Polym. Sci., Part A: Polym. Chem., 12, 455 (1974).

18. H. Matsuda, J. Appl. Polym. Sci., 22, 3371 (1978).

19. R. Jayakumar, M. Rajkumar, R. Nagendran, and S. Nanjundan, J. Macromol. Sci., Pure Appl. Chem., A38(9), 869 (2001).

20. R. Jayakumar, M. Rajkumar, R. Nagendran, and S. Nanjundan, J. Appl. Polym. Sci., 85, 1194 (2002).

21. R. Jayakumar, Y.-S. Lee, and S. Nanjundan, React. Funct. Polym., 55, 267 (2003).

22. R. Jayakumar, R. Arun Prasath, S. Radhakrishnan, and S. Nanjundan, J. Macromol. Sci., Pure Appl. Chem., A39, 853 (2002).

23. P. Rajalingam and G. Radhakrishnan, Polymer, 33, 2214 (1992).

24. R. Jayakumar, Y.-S. Lee, and S. Nanjundan, J. Appl. Polym. Sci., (2003), in press.

25. R. Jayakumar, Y.-S. Lee, M. Rajkumar, and S. Nanjundan, J. Appl. Polym. Sci., (2003), in press.

26. R. Arun Prasath, R. Jayakumar, and S. Nanjundan, J. Macromol. Sci., Pure Appl. Chem., A37(5), 469 (2000).

27. R. Jayakumar, Y.-S. Lee, and S. Nanjundan, Int. J. Polym. Anal. Ch., (2003), in press.

28. R. Jayakumar, S. Radhakrishnan, and S. Nanjundan, React. Funct. Polym., (2003), in press. 